\title{
Factors influencing T-cell turnover in HIV-1-seropositive patients
}

Joseph M. McCune, $, 1,2,3$ Mary Beth Hanley, ${ }^{1}$ Denise Cesar, ${ }^{4}$ Robert Halvorsen, ${ }^{5}$ Rebecca Hoh, ${ }^{4}$ Diane Schmidt, ${ }^{1}$ Eric Wieder, ${ }^{1}$ Steven Deeks, ${ }^{2}$ Scott Siler,${ }^{4}$ Richard Neese,${ }^{4}$ and Marc Hellerstein ${ }^{2,4}$

${ }^{1}$ The Gladstone Institute of Virology and Immunology,

${ }^{2}$ Department of Medicine, San Francisco General Hospital, and

${ }^{3}$ Department of Microbiology and Immunology, University of California-San Francisco, San Francisco, California 94141, USA

${ }^{4}$ Department of Nutritional Sciences, University of California-Berkeley, Berkeley, California 94720, USA

${ }^{5}$ Department of Radiology, San Francisco General Hospital, University of California-San Francisco, San Francisco, California 94141, USA

Address correspondence to: J.M. McCune, The Gladstone Institute of Virology and Immunology, University of California-San Francisco, PO Box 419100, San Francisco, California 94141-9100, USA. Phone: (415) 695-3828; Fax: (415) 826-8449;

E-mail: mmccune@gladstone.ucsf.edu.

Received for publication October 8, 1999, and accepted in revised form December 20, 1999.

HIV-1 disease is associated with pathological effects on T-cell production, destruction, and distribution. Using the deuterated $(2 \mathrm{H})$ glucose method for endogenous labeling, we have analyzed host factors that influence T-cell turnover in HIV-1-uninfected and -infected humans. In untreated HIV-1 disease, the average half life of circulating $\mathrm{T}$ cells was diminished without compensatory increases in cell production. Within 12 weeks of the initiation of highly active antiretroviral therapy (HAART), the absolute production rates of circulating $\mathrm{T}$ cells increased, and normal half-lives and production rates were restored by 12-36 months. Interpatient heterogeneity in the absolute degree of turnover correlated with the relative proportion of naive- and memory/effector-phenotype $\mathrm{T}$ cells in each of the CD4+ and CD8+ populations. The half-lives of naive-phenotype $\mathrm{T}$ cells ranged from 116-365 days (fractional replacement rates of $0.19-0.60 \%$ per day), whereas memory/effector-phenotype T cells persisted with half-lives from 22-79 days (fractional replacement rates of $0.87-3.14 \%$ per day). Naive-phenotype T cells were more abundant, and the halflife of total T cells was prolonged in individuals with abundant thymic tissue, as assessed by computed tomography. Such interpatient variation in T-cell kinetics may be reflective of differences in functional immune reconstitution after treatment for HIV-1 disease.

This article may have been published online in advance of the print edition. The date of publication is available from the JCI website, http://www.jci.org.

J. Clin. Invest. 105:R1-R8 (2000).

\section{Introduction}

HIV-1 disease is marked by progressive loss of CD4+ and CD8+ T cells, leading to immunodeficiency and death. Such T-cell depletion may be secondary to destruction of mature $\mathrm{T}$ cells (1-6) and/or to inhibition of de novo T-cell production (e.g., from resting memory $T$ cells in peripheral lymphoid organs, $\mathrm{T}$ lineage-restricted progenitor cells in the thymus, or multilineage hematopoietic progenitor cells in the bone marrow) (6-9). Establishing the relative contribution of these mechanisms is important for several reasons. First, if HIV-1 effects on T-cell production play a significant role in collapse of the immune system, agents that facilitate $\mathrm{T}$-cell production may find therapeutic utility. Second, sources of T-cell production are nonequivalent: a diverse $\mathrm{T}$-cell receptor (TCR) repertoire may emanate from the thymus, but the potential for such diversity may not reside within the peripheral T-cell compartment, particularly during late stages of HIV-1 disease.

The quantity and quality of T-cell production are especially important after treatment of late-stage patients with highly active antiretroviral therapy (HAART). Higher circulating CD4+ T-cell levels observed in the initial months after such treatment may emanate from cell populations previously sequestered within lymphoid organs $(10,11)$ and/or from de novo production of T-cells $(12,13)$. In most cases, these higher $\mathrm{T}$-cell counts are associated with improved T-cell function against recall antigens (such as cytomegalovirus [CMV]) (14-16) and decreased CD4+ and CD8+ T-cell responses against epitopes associated with HIV-1 (17). Such changes suggest antigen-driven proliferation of clonally distributed memory $\mathrm{T}$ cells, preferentially weighted toward responses against persistent antigen.

We have previously reported that some, but not all, patients with latestage HIV-1 disease have abundant thymic tissue and increased circulating levels of naive-phenotype (CD45RA+CD62L+) CD4+ T cells (18). Using in vivo labeling with deuterated $\left({ }^{2} \mathrm{H}\right)$ glucose, we have also observed that some, but not all, patients demonstrate high levels of Tcell production 12 weeks after the initiation of HAART (12). Because naivephenotype T cells have been shown to turn over more slowly than memory/effector-phenotype T cells in animal models $(3,4,7,19,20)$ and, by indirect measurements, may also turn over more slowly in humans $(6,21,22)$, we hypothesized that differences in turnover among patients may be associated with the relative abundance and the proliferation of memory/effectorphenotype $\mathrm{T}$ cells. In this study, we report cross-sectional and longitudinal analyses of HIV-1-seropositive patients at varying times after the ini- 


\section{Figure 1}

$\mathrm{k}$ and absolute production rates of $\mathrm{CD} 4+$ and CD8+ T cells in HIV-1-seronegative and HIV-1-seropositive subjects who were either untreated or treated with HAART. Values of $\mathrm{k}$ (per day) and of absolute production rates (cells/ $\mu \mathrm{L}$ per day) for peripheral blood CD4+ and CD8+ $T$ cells are shown for different groups of subjects, including HIV1-seronegative subjects (HIV-) and HIV1-seropositive subjects who were either untreated $(\mathrm{HIV}+)$ or treated with HAART for 12 weeks (ST) or for 12-36 months (LT). Some of the data points shown in this figure are from subjects previously described in ref. 8 (see Table 1 for details).
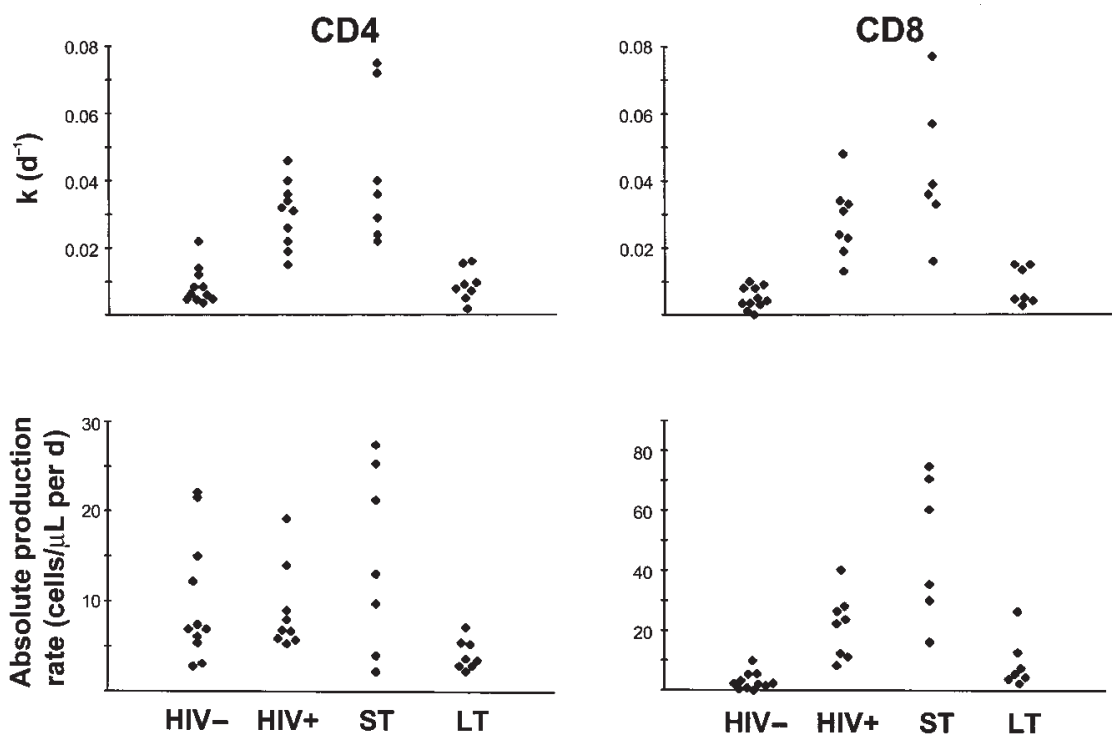

tiation of HAART, correlating turnover of the CD4+ and CD8+ T-cell populations with the relative abundance of naive- and memory/effectorphenotype $\mathrm{T}$ cells and with the amount of residual thymic tissue. We also directly analyze the turnover of purified subpopulations of naive- and memory/effector-phenotype CD4+ and CD8+ T-cell subpopulations in HIV1-seronegative and in HIV-1-seropositive individuals before and after the initiation of antiretroviral therapy.

\section{Methods}

Human subjects. Subjects were recruited by advertisement. Informed consent was obtained for all procedures, and the protocols used in this study were approved by the University of California-San Francisco Committee on Human Research.

Chest tomography. Noncontrast chest computed tomograms (CTs) were performed on a CT scanner (9800 or a helical high-speed scanner; General Electric Co., Milwaukee, Wisconsin, USA) with contiguous $5-\mathrm{mm}$ sections obtained at end expiration from the sternal notch to the xiphoid. A thymic index was scored (by R. Halvorsen) on a grading scale of $0-5$, as described elsewhere (18), with a score of 0 signifying a thymus entirely replaced by fat, and a score of 5 applied to those instances in which the thymus was large enough to be considered hyperplastic or possibly involved with tumor.

Flow cytometry. Naive- or memo- ry/effector-phenotype $\mathrm{CD} 4+$ and CD8+ $\mathrm{T}$ cells were identified as described previously (18, 23), using fluoresceinated antibodies against CD4, CD8, CD45RA, and CD62L. Flow cytometric analysis was performed on a FACScan (Becton Dickinson Immunocytometry Systems, San Jose, California, USA). For each stain, data from 50,000 cells were collected and analyzed on CellQuest software(Becton Dickinson Immunocytometry Systems, San Jose, California, USA). Absolute numbers of CD4+ or CD8+ T-cell populations were calculated by multiplying their fractional representation by absolute cell counts obtained at the San Francisco General Hospital Clinical Laboratories. For sort purification of T-cell subpopulations, CD4+ or CD8+ T cells with the CD45RA+CD62L+ phenotype were retrieved as naive-phenotype $T$ cells on a dual laser (Argon 488 nm,Helium/Neon $633 \mathrm{~nm}$ ) FACS Vantage (Becton Dickinson Immunocytometry Systems) equipped for biocontained procedures with viable, HIV-1-infected cells; all other subpopulations of T cells were collected together as memory/effector-phenotype T cells.

Measurement of T-cell kinetics. The FACS/stable isotope/mass spectrometric method for measuring cell proliferation was used, as described previously $(12,24)$. Briefly, the method involves 3 steps: (a) administration of $\left[6,6-{ }^{2} \mathrm{H}_{2}\right]$ glucose by constant, $24-$ to 48-hour intravenous infusion in the
San Francisco General Hospital General Clinical Research Center, accompanied by blood draws every 6-12 hours during the infusion (to measure enrichments of plasma glucose) and at days 4-7 and days 8-12 after the initiation of the infusion (to measure the fraction of dividing cells labeled during the infusion period that had appeared in the circulation); (b) sort purification of relevant subpopulations of CD4+ or CD8+ T cells (at least 1 million cells each); and (c) determination of the enrichment of ${ }^{2} \mathrm{H}_{2}$-dA in the DNA of purified cell subpopulations using gas chromatography-mass spectrometry (GC-MS). dA was prepared from T-cell DNA by enzymatic hydrolysis (using nuclease P1, snake venom phosphodiesterase I, and alkaline phosphatase) followed by separation on an LC18 SPE column (Supelco, Bellefonte, Pennsylvania, USA). The column was prepared by eluting with $100 \%$ methanol and water $(2 \mathrm{~mL}$ each), followed by the addition of the hydrolyzed DNA sample. The other nucleosides were eluted with a $5 \mathrm{~mL}$ $\mathrm{H}_{2} \mathrm{O}$ wash, and then $\mathrm{dA}$ was eluted with $1.0 \mathrm{~mL}$ of $50 \%$ methanol. After drying under $\mathrm{N}_{2}$ and lyophilization, the $\mathrm{dA}$ pellet was converted to the triacetylaldonitrile derivative of deoxyribose (dR) by addition of $1 \%$ hydroxylamine in 25 $\mathrm{mL}$ pyridine with heating $\left(100^{\circ} \mathrm{C}\right.$ for 1 hour, capped tightly), followed by cooling and addition of 2 drops acetic anhydride (15 minutes at room temperature). The reaction mixture was 
a

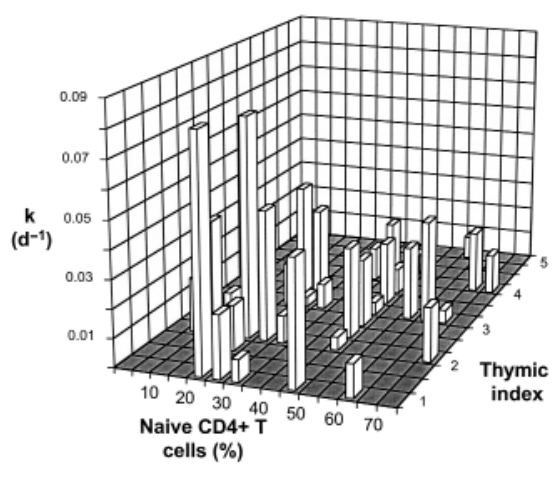

then dried under $\mathrm{N}_{2}$ and extracted with $30 \mathrm{~mL}$ of ethyl acetate for GC-MS analysis of the dR derivative. An HP model 5971 MS with a 5890 GC and autosampler (Hewlett-Packard, Palo Alto, California, USA) was used, with a 30 m DB-225 column. Sample enrichments were calculated by comparison to abundance-corrected standard curves prepared from ${ }^{2} \mathrm{H}_{2}$-dA (12).

Calculation of T-cell kinetic parameters. Kinetic calculations were based on the precursor-product relationship (25, 26) and were carried out as described elsewhere (12). The fractional replacement rate constant ( $k$, per day) was calculated from the differential equation $\mathrm{dB} / \mathrm{dt}=\mathrm{k}(\mathrm{A}-\mathrm{B})$, where A represents the isotope enrichment of newly synthesized DNA strands (reflecting the enrichment of the biosynthetic precursor, deoxyadenosine triphosphate in nuclei of dividing cells) and B is the isotopic enrichment in the mixed product pool (dA in DNA in the total cell population sampled). As discussed (12), this approach will not measure infected cells that are rapidly destroyed in tissues by HIV-1 before entering the circulating pool or cells that are slowly produced and/or released into the circulation after the time of blood sampling; hence, the measurements provided herein represent a minimal estimate of T-cell turnover of various subpopulations. Absolute T-cell production rates were calculated as $\mathrm{k} \times$ pool size, where pool size is the measured blood level ( $\mathrm{T}$ cells $/ \mu \mathrm{L}$ ) on the day of the study. The HIV-1-seronegative controls and the HIV-1-seropositive patients were at steady state or at quasi-steady state for circulating $\mathrm{CD} 4+$ and $\mathrm{CD} 8+\mathrm{T}$ cells
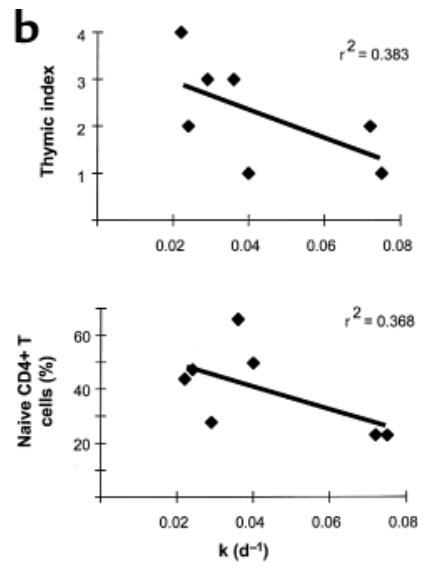

during the 24- to 48-hour labeling period and the 4- to 12-day follow-up blood drawing period. Data from some of these subjects have in part been reported previously (12). To ensure comparability with the more recent subjects, all previous GC-MS chromatograms were reintegrated by the same individual (D. Cesar).

Statistical analysis. Groups were compared by 1-way ANOVA with Dunn/Bonferroni follow-up at a procedure-wise error rate of $5 \%$. Results for $\mathrm{CD} 4+\mathrm{T}$ cells were compared with those of CD8+ T cells within groups by the paired $t$ test. Multiple regressions of the data in Figure 2a were performed as 1 dependent and 2 independent variables (e.g., $\mathrm{k}$ as a function of thymic index and percent naive $T$ cells) using an SPSS program (SPSS Inc., Chicago, Illinois, USA).

\section{Results}

Turnover of $C D 4+$ and $C D 8+T$ cells as a function of time after HAART. To evaluate $\mathrm{T}$-cell production before and after the initiation of treatment, 4 groups of HIV-1-seronegative and HIV-1-positive subjects were studied using the deuterated glucose method: (a) 11 healthy, HIV-1-seronegative subjects (7 men, 4 women); (b) 11 viremic, untreated HIV-1-seropositive subjects (8 men, 3 women) with a mean nadir CD 4 count of $239 \pm 59$ cells $/ \mu \mathrm{L}$ (mean \pm SEM; range $=25-620$ ); (c) 7 HIV1 -seropositive subjects (all men) who had received a 12-week course of HAART after being antiretroviral therapy-naive and who, at the time of analysis, had undetectable viral loads ( $<500$ copies per milliliter) and a mean CD 4 count of $332 \pm 69$ cells $/ \mu \mathrm{L}$ (range

\section{Figure 2}

Relationship between k, percent naive CD4+ $\mathrm{T}$ cells, and thymic index. (a) Correlations between $k$ of total CD4+ T cells, percent naive CD4+ $T$ cells, and thymic index are derived from the data presented in Table 1 . (b) Pairwise correlations in the short-term HAART group between $k$ of CD4+ T cells and thymic index (top) and between $k$ and percent naive-phenotype CD4+ T cells (bottom).
=90-629), relative to a mean pretreatment nadir of $186 \pm 44$ cells $/ \mu \mathrm{L}$ (range = 77-335); and (d) 8 HIV-1-seropositive subjects (all men) whose viral loads had been effectively suppressed on HAART for periods ranging from 12 to 36 months and who had a mean CD 4 count of $587 \pm 122$ cells $/ \mu \mathrm{L}$ $($ range $=240-1,261)$ relative to a mean pretreatment nadir of $165 \pm 76$ cells $/ \mu \mathrm{L}$ (range $=7-603$ ). Table 1 presents detailed information about the age, CD4 nadir, viral loads, CD4+ and CD8+ T-cell counts, and antiretroviral treatment history of these individuals.

The fractional replacement rates $(\mathrm{k})$ and the absolute production rates for the circulating CD4+ and CD8+ T-cell populations of these subjects are graphed in Figure 1 and listed in Table 1. As reported previously (12), the fractional replacement rates of circulating $\mathrm{CD} 4+$ or $\mathrm{CD} 8+\mathrm{T}$ cells were higher in untreated HIV-1-seropositive subjects relative to HIV-1-seronegative subjects (for CD4+ T cells: $0.030 \pm 0.010 / d$ vs. $0.0085 \pm 0.0017 / \mathrm{d}$; for $\mathrm{CD} 8+\mathrm{T}$ cells: $0.028 \pm 0.011 / \mathrm{d}$ vs. $0.0050 \pm 0.0010 / \mathrm{d}$ ) $(P<0.0002$ for $\mathrm{CD} 4+$ and CD8+ T cells). In the case of CD4+ $\mathrm{T}$ cells, the absolute production rates were essentially the same in the setting of untreated HIV-1 infection $(8.6 \pm 1.4$ cells $/ \mu \mathrm{L}$ per day vs. $9.9 \pm 2.0$ cells $/ \mu \mathrm{L}$ per day in HIV1-seronegative controls), whereas for CD8+ $\mathrm{T}$ cells, the absolute production rates were significantly higher in untreated subjects $(22.8 \pm 4.2$ cells $/ \mu \mathrm{L}$ per day) than in HIV-1-seronegative subjects ( $3.0 \pm 0.9$ cells $/ \mu \mathrm{L}$ per day) ( $P<$ $0.003)$. After 12 weeks of treatment with effective HAART, the fractional replacement rates of circulating CD4+ and $\mathrm{CD} 8+\mathrm{T}$ cells did not change signifi- 
Table 1

T-cell kinetics and clinical characteristics in individual subjects

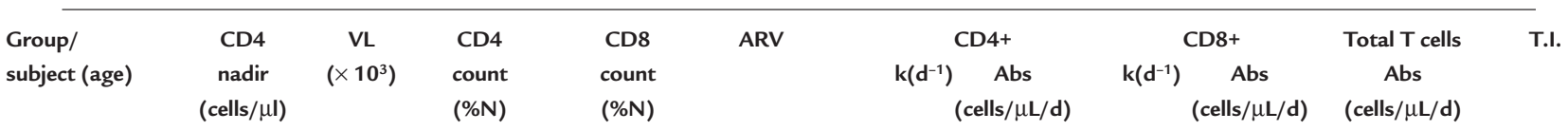

I) HIV- Healthy controls

$\begin{array}{lccccc}1(29) & - & - & 1509(70) & 574(59) & - \\ 2(27) & - & - & 1576(73) & 989(\mathrm{NA}) & - \\ 3(29) & - & - & 1317(60) & 594(45) & - \\ 4(38) & - & - & 891(32) & 226(47) & - \\ 5(\mathrm{NA}) & - & - & 1142(\mathrm{NA}) & 664(\mathrm{NA}) & - \\ 6(\mathrm{NA}) & - & - & 1971(\mathrm{NA}) & 902(33) & - \\ 7(45) & - & - & 682(28) & 607(17) & - \\ 8(34) & - & - & 875(58) & 375(79) & - \\ 9(52) & - & - & 1792(65) & 403(48) & - \\ 10(29) & - & - & 632(49) & 294(65) & - \\ 11(34) & - & - & 875(52) & 746(46) & - \\ \text { Mean } \pm \text { SEM } & \text { NA } & \text { NA } & 1206(54) & 579(44) & \\ & & & \pm 138( \pm 5) & \pm 73( \pm 8) & \end{array}$

(11) (11)

$\begin{array}{cc}0.0046 & 6.9 \\ 0.0140 & 22.1 \\ 0.0046 & 6.1 \\ 0.0035 & 3.1 \\ 0.0059 & 6.9 \\ 0.0083 & 12.2 \\ 0.0220 & 15.0 \\ 0.0084 & 7.4 \\ 0.0120 & 21.5 \\ 0.0045 & 2.8 \\ 0.0062 & 5.4 \\ 0.0085 & 9.9 \\ \pm .0017 & \pm 2.0\end{array}$

$\begin{array}{cccr}0.0041 & 2.3 & 9.2 & 3 \\ 0.0100 & 9.9 & 32.0 & 4 \\ 0.0000 & 0.0 & 6.1 & 2 \\ 0.0035 & 0.8 & 3.9 & 3 \\ 0.0079 & 5.3 & 12.2 & \mathrm{NA} \\ 0.0034 & 2.0 & 14.2 & \mathrm{~N} A \\ 0.0090 & 5.5 & 20.5 & 1 \\ 0.0011 & 0.4 & 7.8 & 5 \\ 0.0080 & 3.2 & 24.7 & 1 \\ 0.0050 & 1.5 & 4.3 & 3 \\ 0.0030 & 2.2 & 7.6 & 4 \\ 0.0050 & 3.0 & 12.9 & - \\ \pm .0010 & \pm 0.9 & \pm 2.7 & \end{array}$

(11) (11)

(11) (11)

(11)

II) HIV+, untreated

\begin{tabular}{|c|c|c|c|c|c|c|c|c|c|c|}
\hline $1(39)$ & 123 & 276 & $142(31)$ & $515(30)$ & - & 0.046 & 6.8 & 0.024 & 12.4 & 19.2 \\
\hline $2(47)$ & 262 & 5.8 & $298(12)$ & $1175(10)$ & - & 0.019 & 5.7 & 0.019 & 22.3 & 28.0 \\
\hline $3(36)$ & 25 & 44.9 & $35(4)$ & $850(19)$ & - & - & - & 0.033 & 28.1 & - \\
\hline $4(53)$ & 177 & 65.7 & $250(11)$ & $695(8)$ & - & 0.036 & 9.0 & 0.034 & 23.7 & 32.7 \\
\hline $5(37)$ & 204 & 70.7 & $350(24)$ & $660(30)$ & - & 0.015 & 5.3 & 0.013 & 11.2 & 16.5 \\
\hline $6(34)$ & 114 & 2.0 & 183(48) & $361(46)$ & - & 0.032 & 5.9 & 0.023 & 8.3 & 14.2 \\
\hline $7(42)$ & 620 & 21.5 & $740(59)$ & 1173(29) & 3TC/D4T & 0.026 & 19.2 & 0.031 & 36.4 & 55.6 \\
\hline $8(39)$ & 92 & 107.4 & $168(23)$ & $838(17)$ & - & 0.040 & 6.7 & 0.048 & 40.2 & 46.9 \\
\hline $9(34)$ & 236 & 43.0 & $236(\mathrm{NA})$ & 1859(NA) & - & 0.034 & 8.6 & - & - & - \\
\hline $10(45)$ & 609 & 10.0 & $636(69)$ & $1145(44)$ & AZT/3TC & 0.022 & 14.0 & - & - & - \\
\hline $11(50)$ & 172 & 440 & $172(\mathrm{NA})$ & $702(\mathrm{NA})$ & - & 0.031 & 5.3 & - & - & - \\
\hline \multirow[t]{3}{*}{ Mean \pm SEM } & 239 & 98.8 & $292(31)$ & $906(26)$ & & $0.030^{\mathrm{A}}$ & 8.6 & $0.028^{A}$ & $22.8^{A}$ & $30.4^{\mathrm{A}}$ \\
\hline & \pm 59 & \pm 41.3 & $\pm 64( \pm 8)$ & $\pm 125( \pm 5)$ & & \pm .010 & \pm 1.4 & \pm .011 & \pm 4.2 & \pm 6.0 \\
\hline & (11) & (11) & (11) & (11) & & (10) & (10) & (8) & (8) & (7) \\
\hline
\end{tabular}

cantly relative to those observed in untreated HIV-1-seropositive subjects (for CD4+ T cells: $0.043 \pm 0.011 / \mathrm{d}$ vs. $0.030 \pm 0.010 / \mathrm{d}$; for CD8+ T cells: 0.040 $\pm 0.010 / \mathrm{d}$ vs. $0.028 \pm 0.011 / \mathrm{d})$. There was, however, an increase in the absolute production rates (to $15.7 \pm 4.2$ cells $/ \mu \mathrm{L}$ per day for CD4+ T cells and to $44.3 \pm$ 11.4 cells/ $\mu \mathrm{L}$ per day for CD8+ T cells), which reached statistical significance for CD8+ T cells $(P<0.001)$ and for total $\mathrm{T}$ cells (from $30.4 \pm 6.0$ to $69.2 \pm 14.8$ cells $/ \mu \mathrm{L}$ per day; $P<0.001)$. Hence, the decrease in circulating CD4+ T cells observed in untreated HIV-1-seropositive subjects (to a mean CD4+ T-cell count of $294 \pm 64$ cells $/ \mu \mathrm{L}$ ) was associated with an increased fractional replacement rate that was not compensated by an increased rate of absolute production; in contrast, the increase in CD4+ T cells observed 12 weeks after the initiation of effective therapy (to a mean of $332 \pm 69$ cells $/ \mu \mathrm{L}$ ) was associated with higher rates of T-cell production. As discussed later, these kinetics did not persist: at later time points (12-36 months) after the initiation of HAART, the fractional replacement and absolute production rates for the CD4+ and the CD8+ $\mathrm{T}$ cell subpopulations reverted back toward those observed in HIV-1-seronegative subjects.

Relationship between $k$, percent memo$\mathrm{ry} /$ effector-phenotype $T$ cells, and thymic abundance. The analysis just described revealed general trends in $\mathrm{CD} 4+$ and CD8+ T-cell turnover as a function of HIV-1 disease status and treatment. On inspection of Figure 1 and Table 1 , it is also notable that there is a high degree of interpatient variability amongst the k's observed for each group, especially the HIV-1-seroposi- tive subjects 12 weeks after the initiation of treatment. We hypothesized that such heterogeneity may be due to interpatient variations in the subpopulations of $\mathrm{T}$ cells that predominate and proliferate after the initiation of HAART. This hypothesis was based in part on the previous observation that some, but not all, untreated HIV-1-seropositive subjects (aged 20-59 years) have abundant thymic tissue as observed by CT and that the presence of such tissue is correlated with the circulating percentage and absolute number of circulating naivephenotype (CD45RA+CD62L+) CD4+ T cells (18). Because such cells are likely to have a slower turnover (lower k) than memory/effector cells, the $\mathrm{k}$ of the total CD4+ T cell population may vary depending on their relative abundance. 
Table 1, continued

T-cell kinetics and clinical characteristics in individual subjects

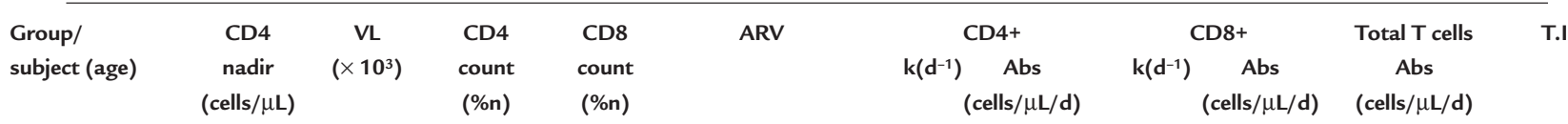

III) HIV+, short-term HAART

\begin{tabular}{|c|c|c|c|c|c|c|c|c|c|c|}
\hline $1(47)$ & 135 & $<0.5$ & $296(23)$ & $920(14)$ & $\mathrm{R} / \mathrm{S} / 3 \mathrm{TC}$ & 0.072 & 21.3 & 0.077 & 70.7 & 92.0 \\
\hline $2(38)$ & 335 & $<0.5$ & $629(50)$ & $1058(23)$ & $\mathrm{R} / \mathrm{S} / \mathrm{D} 4 \mathrm{~T} / 3 \mathrm{TC}$ & 0.040 & 25.4 & 0.057 & 60.4 & 85.3 \\
\hline $3(29)$ & 77 & $<0.5$ & $363(66)$ & $987(37)$ & $\mathrm{R} / \mathrm{S} / \mathrm{D} 4 \mathrm{~T} / 3 \mathrm{TC}$ & 0.036 & 13.1 & 0.036 & 35.5 & 48.6 \\
\hline $4(43)$ & 83 & $<0.5$ & $135(28)$ & $776(10)$ & $\mathrm{R} / \mathrm{S} / \mathrm{AZT} / 3 \mathrm{TC}$ & 0.029 & 4.0 & 0.039 & 30.1 & 36.9 \\
\hline $5(45)$ & 289 & $<0.5$ & $365(23)$ & $2277(7)$ & $\mathrm{R} / \mathrm{S} / \mathrm{AZT}$ & 0.075 & 27.5 & 0.033 & 74.9 & 102.4 \\
\hline $6(37)$ & 300 & $<0.5$ & $445(44)$ & 1010(31) & E/D4T/3TC & 0.022 & 9.8 & 0.016 & 16.2 & 26.0 \\
\hline $7(33)$ & 84 & $<0.5$ & $90(47)$ & $575(15)$ & N/D4T/DDI/HU & 0.024 & 2.2 & NA & NA & NA \\
\hline & \pm 44 & (7) & $\pm 69( \pm 6)$ & $\pm 208( \pm 4)$ & & \pm .011 & \pm 4.2 & \pm .010 & \pm 10.8 & \pm 14.8 \\
\hline & (7) & & (7) & $(7)$ & & $(7)$ & (7) & $(7)$ & $(6)$ & (6) \\
\hline
\end{tabular}

IV) HIV +, long-term HAART

$\begin{array}{lccccc}1(42) & 381 & <0.5 & 917(34) & 943(29) & \text { I/3TC/D4T } \\ 2(50) & 13 & <0.5 & 608(52) & 1976(21) & \text { I/3TC/D4T } \\ 3(27) & 603 & <0.5 & 1261(51) & 880(28) & \text { 3TC/D4T } \\ 4(34) & 7 & <0.5 & 364(33) & 449(16) & \text { I/3TC/D4T } \\ 5(38) & 87 & <0.5 & 330(25) & 898(29) & \text { I/3TC/D4T } \\ 6(51) & 13 & <0.5 & 403(48) & 1218(38) & \text { I/3TC/D4T } \\ 7(48) & 135 & <0.5 & 240(22) & 854(14) & \text { N/3TC/AZT } \\ 8(30) & 77 & <0.5 & 571(51) & 957(45) & \text { R/S/3TC/D4T } \\ \text { Mean } \pm \text { SEM } & 165 & <0.5 & 587(40) & 1028(28) & \\ & \pm 76 & (8) & \pm 122( \pm 4) \pm 152( \pm 4) & \end{array}$

(8)

$\begin{array}{cc}0.0078 & 7.2 \\ 0.0091 & 5.5 \\ 0.0018 & 2.3 \\ 0.0096 & 3.5 \\ 0.0160 & 5.3 \\ 0.0071 & 2.9 \\ 0.0154 & 3.7 \\ 0.0050 & 2.9 \\ 0.0090^{\mathrm{B}, \mathrm{C}} & 4.2^{\mathrm{C}} \\ \pm .0017 & \pm 0.6\end{array}$

(8)

$\begin{array}{cc}- & - \\ 0.0134 & 26.5 \\ 0.0027 & 2.4 \\ 0.0150 & 7.5 \\ 0.0050 & 4.5 \\ 0.0046 & 5.6 \\ 0.0150 & 12.8 \\ 0.0041 & 3.9 \\ 0.0085^{\mathrm{B}, \mathrm{C}} & 9.0^{\mathrm{C}} \\ \pm .0021 & \pm 3.2\end{array}$

(7)

(7)

$\begin{array}{cc}- & 1 \\ 32.0 & 3 \\ 4.7 & 4 \\ 10.8 & 2 \\ 9.8 & 1 \\ 8.5 & 4 \\ 16.5 & 2 \\ 6.8 & 4 \\ 12.7 \mathrm{C} & \\ \pm 3.5 & \end{array}$

Plasma HIV-1 viral load (VL) was measured by the Chiron bDNA method. CD4+ and CD8+ T-cell counts were determined by fluorescence-activated cell sorting. Abs, absolute production rate; CD4 nadir, lowest blood CD4 count documented in subject's medical chard; T.I., thymic index by CT scan; -, not measured or not appropriate; NA, not available; age, in years; ARV, antiretroviral therapy at time of study; \%n, percent naive-phenotype cells in population; 3TC, lamivudine; AZT, zidovudine; D4T, stauvidine; E, efavirenz; HU, hydroxyurea; I, indinavir; N, nelfinavir; R, ritonavir; S, saquinavir; Total T cells, total of CD4 plus CD8 proliferation. Absolute production (cells/ $\mu \mathrm{L} /$ day) was calculated from $\mathrm{k} \times \mathrm{CD} 4$ or CD8 count. Some of the data from this table were previously reported (ref. 8) from Groups I (subjects \#1-6, 8,9,11), II (subjects \#6-11), and III (subjects \#1-5). Results for k of CD8+ T cells in subject \#3, Group I, is different from value reported in reference 8 (data integration error found and corrected). Statistics: ${ }^{A} P<0.0083$ vs $\mathrm{HIV}-$, healthy controls; ${ }^{\mathrm{B} P}<0.0083$ vs $\mathrm{HIV+}$, untreated; ${ }^{C} P<0.0083$ vs HIV+, short-term HAART.

Accordingly, we correlated thymic index (T.I.), naive CD4+ T cell percent, and the fractional replacement rate $(\mathrm{k})$ for the total CD4+ T-cell population. These parameters tended to segregate into discrete clusters (Figure 2a). Those subjects with a high thymic index were more likely to have a higher percentage of naive-phenotype $\mathrm{CD} 4+\mathrm{T}$ cells and a low $\mathrm{k}$ for the total circulating CD4+ T-cell population. Similar results were observed for CD8+ T cells. Results of multiple regression analysis (Figure 2a) for CD4+ $\mathrm{T}$ cells were as follows: $\mathrm{k}$ increased as a function of decreased T.I. and decreased naive T-cell percent: $r^{2}=0.20, P=0.03$; T.I. increased as a function of decreased $\mathrm{k}$ and increased naive T-cell percent: $r^{2}=0.28, P=0.007$; naive $\mathrm{T}$-cell percent increased as a function of decreased $\mathrm{k}$ and increased T.I.: $r^{2}=0.27, P=0.008$. Results of pair- wise, Pearson regression analysis were also revealing, particularly in the short-term HAART group: significant inverse correlations were documented for $\mathrm{k}$ versus T.I. $\left(r^{2}=0.38\right)$ and $\mathrm{k}$ versus naive $\mathrm{T}$ cell percent $\left(r^{2}=0.37\right)$ for $\mathrm{CD} 4+\mathrm{T}$ cells (Figure $2 \mathrm{~b}$ ). In contrast, no relationship was found between thymic index and the percentage of naive-phenotype $\mathrm{CD} 8+\mathrm{T}$ cells (data not shown; see also ref. 18). These results suggested that the $\mathrm{k}$ of the total CD4+ T-cell population in the shortterm HAART group may be low when the percent naive $T$ cells is high, perhaps because naive-phenotype cells turn over less quickly.

Direct measurement of $k$ for naive- and memory/effector-phenotype $T$ cells. To determine directly the fractional replacement rates $(\mathrm{k})$ of naive- and memory/effector-phenotype CD4+ and $\mathrm{CD} 8+\mathrm{T}$ cells in subjects with and without HIV-1 disease, these subpopulations were purified by multiparameter cell sorting from the peripheral blood of subjects who had been infused with $\left[{ }^{2} \mathrm{H}\right]$ glucose, including: HIV-1-seronegative controls $(n=11)$, untreated HIV-1-seropositive subjects $(n=10)$, and subjects treated with HAART for $12-36$ months $(n=8)$. In all groups, the mean $\mathrm{k}$ of the memory/effector-phenotype populations of both CD4+ and CD8+ T cells was consistently higher than the mean $\mathrm{k}$ of the respective naive populations (Table 2 ). The average half-lives calculated from these values of $\mathrm{k}(0.693 / \mathrm{k})$ ranged from 22 to 79 days for memory/effector-phenotype CD4+ T cells and 22 to 63 for memory/effector-phenotype CD8 $+\mathrm{T}$ cells, whereas naive-phenotype $\mathrm{T}$ cells had longer half-lives (116-365 days). These calculated halflives are similar to those observed in 
Figure 3

Biphasic kinetics of memory/effector-phenotype CD4+ and CD8+ T cells. Incorporation/decay kinetics for memory/effector- and naive-phenotype $T$ cells. Results from a healthy, HIV-1-seronegative control subject are shown (as enrichment of $\mathrm{dA}$ isolated from the DNA of sorted subpopulations) with $\left[{ }^{2} \mathrm{H}\right]$ glucose labeling over a 4-day period (arrow) and blood sampling on days 4 , $10,18,30$, and 40. Subpopulations isolated: $M / E$, memory/effector; $N$, naive; $T$, total. Left: CD4+ T cells. Right: CD8+ T cells.

previous studies of T-cell turnover in rodents $(7,19,20)$ and nonhuman primates $(3,4)$. Interestingly, the mean k's of memory/effector-phenotype CD4+ and CD8+ $\mathrm{T}$ cells were increased in HIV-1-seropositive subjects who were untreated relative to uninfected controls or subjects on long-term HAART $(P<0.001)$; in addition, the absolute production rate of memory/effector-phenotype CD8+ T cells was increased in HIV-1-seropositive subjects who were untreated relative to uninfected controls or subjects on long-term HAART $(P<0.001)$.

Die-away curves of labeled T-cell subpopulations. Prolonged sampling protocols were carried out in some subjects to characterize the incorporation and decay kinetics of the various T-cell subpopulations. An example is shown for CD4+ and CD8+ $\mathrm{T}$ cells in a healthy, HIV-1-seronegative control subject (Figure 3). In this instance, the intravenous infusion of $\left[{ }^{2} \mathrm{H}\right]$ glucose was carried out for 4 days and blood samples were obtained of days $4,10,18,30$, and 40 . Naive- and memory/effectorphenotype as well as total $T$ cells were sort purified at each time point. After cessation of label administration, memory/effector-phenotype $\mathrm{T}$ cells (both CD4+ and CD8+) were found to exhibit biphasic kinetics: an initial rapid die-away, or delabeling, phase followed by persistence of a relatively constant level of labeling for at least several weeks. This second phase of memory/effector-phenotype T-cell labeling closely paralleled the kinetics of naive-phenotype T cells (Figure 3).

A likely explanation for these results is that the memory/effector-phenotype population is in fact composed of more than one kinetic subset:
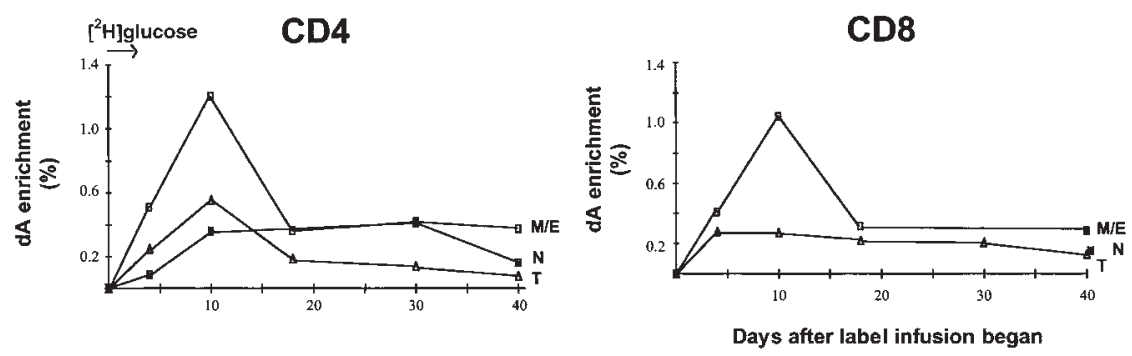

"effector" type and "true memory" type T cells. Indeed, these curves (Figure 3) are reminiscent of those obtained after antigen stimulation of $T$ cells in rodents (reviewed in ref. 20), in which an initial period of expansion is followed by a phase in which many effector cells die and then by one characterized by long-term persistence of true memory cells. If, indeed, such kinetic heterogeneity exists within the "memory/effector" phenotype subpopulation of T cells, the relative proportion of effectortype versus memory-type $T$ cells in an individual introduces yet another factor that can influence the overall kinetics of T-cell turnover.

Normalization of CD4+ and CD8+ T-cell turnover as a function of time after therapy. In contrast to the high turnover state observed in some HIV-1-seropositive subjects 12 weeks after the initiation of potent antiretroviral therapy, the $\mathrm{k}$ and absolute production rates of the total circulating $\mathrm{CD} 4+$ and $\mathrm{CD} 8+\mathrm{T}$ cell populations returned toward normal levels at later time points (12-36 months after the initiation of treatment) (Figure 1; Table 1; $P<0.008$ compared with the short-term HAART group). This change was followed prospectively in 2 individuals, both of whom were first studied 12 weeks after the initiation of therapy and found to have high k's for $\mathrm{CD} 4+$ and $\mathrm{CD} 8+\mathrm{T}$ cells (Table 1: group III, nos. 1 and 3). After 18 months of therapy, the turnover of each cell subpopulation in each individual was decreased substantially (Figure 4 and Table 1: group IV, nos. 7 and 8 , respectively).

At 12-36 months after the initiation of therapy, HIV-1-infected subjects continued to demonstrate a relation- ship between increased thymic abundance and increased percentage and absolute number of circulating naive CD4+ and CD8+ $T$ cells (data not shown). There was no relationship, however, between the fraction of naive-phenotype $\mathrm{CD} 4+\mathrm{T}$ cells and the $\mathrm{k}$ of the total CD4+ or CD8+ T-cell populations: in all cases, the turnover of these subpopulations was low and within the range of that found in HIV1 -seronegative subjects (Table 1 ). Furthermore, the memory/effector-phenotype T-cell subpopulations at months 12-36 demonstrated k's that were significantly lower than those observed in the untreated HIV1 -seropositive group $(P<0.001)$ and not significantly different from those found in HIV-1-seronegative subjects (Table 2). These results indicate that cells within the memory/effector-phenotype subpopulation turn over at different rates as a function of disease status and time after the initiation of treatment. Possibly, such differences may be attributable to the relative abundance of memory versus effector $\mathrm{T}$ cells within this subpopulation.

\section{Discussion}

Studies of cell turnover in HIV-1 disease have usually focused on a single variable: the presence or absence of virus. The studies reported herein suggest that it is also important to consider the immunobiology of the host. In particular, the turnover of circulating CD4+ and $\mathrm{CD} 8+\mathrm{T}$ cells appears to be related to variables inclusive of thymic abundance, percent circulating naive- and memory/effector-phenotype $T$ cells, the composition of the memory/effector population itself, and time after the initiation of antiretroviral therapy. 


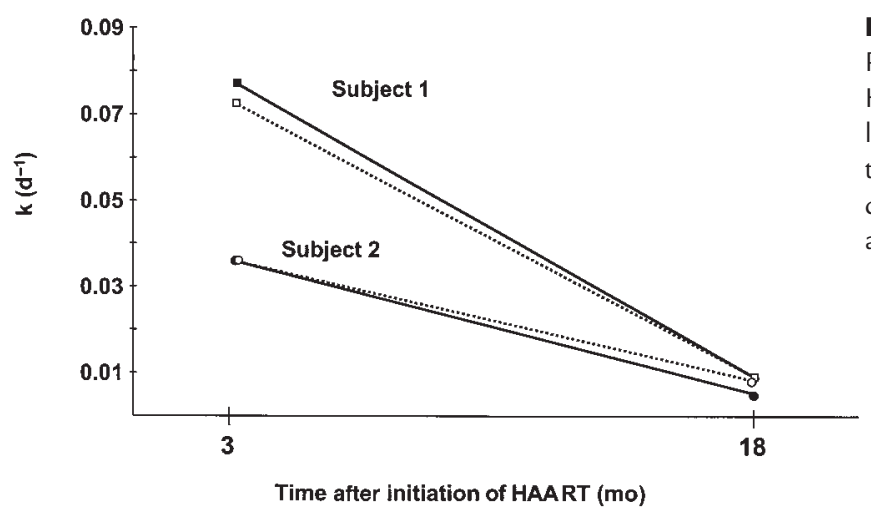

Our most striking finding relates to the normalization of circulating CD4+ and $C D 8+T$ cell turnover as a function of time after therapy. In untreated disease, the fractional replacement rates of both T-cell populations is higher than those found in HIV-1-seronegative controls. These results are consistent with those reported previously in HIV-1-infected humans $(1,2,5,6)$ and in simian immunodeficiency virus-infected nonhuman primates ( 3 , 4). At 12 weeks after the initiation of therapy, these rates remain high, but there is also evidence of increased rates of cell production $(12,13)$. By 12-36 months of therapy, the fractional replacement rates (half-lives) of the circulating CD4+ and CD8+ T-cell populations return toward normal values. By inference, there may exist timedependent variations in the stimuli that drive T-cell proliferation after therapy.

Proliferation of circulating T-cell populations after 12 weeks of therapy was most pronounced in subjects with a high percentage of circulating mem-

\section{Figure 4}

Prospective analysis of $k$ as a function of time after initiation of HAART. Values for $k$ (per day) for peripheral blood CD4+ (dotted lines) and CD8+ T cells (solid lines) for 2 HIV-1-seropositive subjects treated for 3 or for 18 months with HAART. Table 1 provides more complete data for subject 1 (see group III, no. 1 and group IV, no. 7) and subject 2 (see group III, no. 3 and group IV, no. 8). ory/effector-phenotype CD4+ and $\mathrm{CD} 8+\mathrm{T}$ cells (Figure $2 \mathrm{~b}$ ). Because such cells are triggered to divide as a result of signaling through the T-cell receptor, it is possible that they are responding to high loads of exogenous antigens (i.e., those associated with infectious agents prevalent in subjects with late-stage HIV-1 disease). Alternatively, proliferation of memory/effector-phenotype cells might be induced by antigen-independent stimuli (e.g., cytokines such as IL-2 and/or IL-7) as part of a compensatory mechanism to increase total body T-cell reserves. In either case, proliferation of such cells may subside over time as exogenous antigens are cleared and/or as $\mathrm{T}$ cell counts return toward normal.

Our results suggest additionally that the presence or absence of thymic output of $\mathrm{T}$ cells may play an important role in determining the kinetics of $\mathrm{T}$ cells in HIV-1 disease. HIV-1-seropositive subjects with abundant thymus were noted to have higher circulating levels of naive-phenotype $T$ cells and lower turnover rates for the total CD4+ $\mathrm{T}$ cell population. When directly measured using the FACS/stable isotope/mass spectrometric method $(12,24)$, the turnover of the naive-phenotype (CD45RA+CD62L+) subpopulation was consistently lower than that of the memory/effector-phenotype subpopulations of $\mathrm{CD} 4+$ and $\mathrm{CD} 8+\mathrm{T}$ cells, as has been reported previously for human CD45RA+ cells using Ki-67 as a marker for cell proliferation (6) or upon analysis of radiation-induced chromosomal damage $(21,22)$. These characteristics suggest that the phenotypically defined (CD45RA+CD62L+) naive subpopulation of $\mathrm{CD} 4+$ and $\mathrm{CD} 8+\mathrm{T}$ cells in adult humans is, at least in part, composed of recent thymic emigrants. Such a conclusion is supported by recent studies demonstrating that TCR rearrangement excision circles may be found at high frequency within this subpopulation $(27,28)$ and by the observation that this population increases rapidly after therapy in those subjects with an abundant thymus by CT (29).

Table 2

Kinetics of memory/effector $(\mathrm{m} / \mathrm{e})$ and naive $(\mathrm{n})$ phenotype T cells in different groups

\begin{tabular}{|c|c|c|c|c|c|c|c|c|c|c|c|c|}
\hline \multirow[b]{3}{*}{ Group } & \multicolumn{6}{|c|}{$k\left(d^{-1}\right)$} & \multicolumn{6}{|c|}{ Absolute production (cells/ $\mu \mathrm{L} / \mathrm{d}$ ) } \\
\hline & \multicolumn{3}{|c|}{ CD4 } & \multicolumn{3}{|c|}{ CD8 } & \multicolumn{3}{|c|}{ CD4 } & \multicolumn{3}{|c|}{ CD8 } \\
\hline & $\mathrm{m} / \mathrm{e}$ & naive & mixed & $\mathrm{m} / \mathrm{e}$ & naive & mixed & $\mathrm{m} / \mathrm{e}$ & naive & mixed & $\mathrm{m} / \mathrm{e}$ & naive & mixed \\
\hline HIV-, healthy & 0.0087 & 0.0037 & 0.0085 & $0.0175^{\mathrm{A}}$ & 0.0034 & 0.0050 & 5.2 & 2.9 & $10.0^{\mathrm{A}}$ & $6.8^{\mathrm{A}}$ & 1.1 & 3.0 \\
\hline controls & $\begin{array}{c} \pm .0011 \\
\quad(8)\end{array}$ & $\begin{array}{c} \pm .0017 \\
(5)\end{array}$ & $\begin{array}{c} \pm .0017 \\
(11)\end{array}$ & $\begin{array}{c} \pm .0041 \\
(5)\end{array}$ & $\begin{array}{c} \pm .0019 \\
(4)\end{array}$ & $\begin{array}{c} \pm .0010 \\
(11)\end{array}$ & $\begin{array}{c} \pm 1.2 \\
(7)\end{array}$ & $\begin{array}{c} \pm 1.2 \\
(6)\end{array}$ & $\begin{array}{c} \pm 1.8 \\
(12)\end{array}$ & $\begin{array}{c} \pm 2.5 \\
(3)\end{array}$ & $\begin{array}{l} \pm .5 \\
(4)\end{array}$ & $\begin{array}{c} \pm 2.9 \\
(11)\end{array}$ \\
\hline $\begin{array}{l}\mathrm{HIV+}, \\
\text { untreated }\end{array}$ & - & - & $\begin{array}{c}0.030^{\mathrm{B}} \\
\pm .0031 \\
(10)\end{array}$ & $\begin{array}{c}0.0314^{\mathrm{B}} \\
\pm .0031 \\
(6)\end{array}$ & $\begin{array}{l}{ }^{4} 0.0060 \\
\pm .0030 \\
\quad(3)\end{array}$ & $\begin{array}{c}0.0281^{\mathrm{B}, \mathrm{A}} \\
\pm .0038 \\
(8)\end{array}$ & - & - & $\begin{array}{c}8.6 \\
\pm 1.5 \\
(10)\end{array}$ & $\begin{array}{c}20.0^{\mathrm{B}, \mathrm{A}} \\
\pm 3.9 \\
(6)\end{array}$ & $\begin{array}{c}1.1 \\
\pm 0.4 \\
(3)\end{array}$ & $\begin{array}{c}22.8^{\mathrm{B}, \mathrm{A}} \\
\pm 4.1 \\
(8)\end{array}$ \\
\hline $\mathrm{HIV}+$ & $0.0104^{c}$ & $=0.0019$ & $0.0097^{C, A}$ & $0.0110^{\mathrm{C}, \mathrm{C}}$ & 0.0036 & $0.0085^{C}$ & $3.2^{\mathrm{A}}$ & 0.2 & $4.2^{A}$ & $9.8^{\mathrm{A}}$ & 1.1 & $9.0^{\mathrm{C}, \mathrm{A}}$ \\
\hline $\begin{array}{l}\text { Long-term } \\
\text { HAART }\end{array}$ & $\begin{array}{c} \pm .0016 \\
(8)\end{array}$ & $\begin{array}{c} \pm .0017 \\
(5)\end{array}$ & $\begin{array}{c} \pm .0009 \\
(8)\end{array}$ & $\begin{array}{c} \pm .0030 \\
(6)\end{array}$ & $\begin{array}{c} \pm .0015 \\
(6)\end{array}$ & $\begin{array}{c} \pm .0021 \\
(7)\end{array}$ & $\begin{array}{c} \pm 0.5 \\
(7)\end{array}$ & $\begin{array}{c} \pm 0.1 \\
(4)\end{array}$ & $\begin{array}{c} \pm 0.6 \\
(8)\end{array}$ & $\begin{array}{c} \pm 3.5 \\
(5)\end{array}$ & $\begin{array}{c} \pm 0.6 \\
(5)\end{array}$ & $\begin{array}{c} \pm 3.1 \\
(7)\end{array}$ \\
\hline
\end{tabular}

Data shown are mean \pm S.E.M. Numbers in parentheses $=\mathrm{n} .-$, not done. Statistics: ${ }^{A} P<0.01$ vs naive-phenotype T cells. ${ }^{B} P<0.01$ vs HIV- healthy control group. ${ }^{C} P<0.01$ vs $\mathrm{HIV}+$, untreated group. 
The results reported here for memory/effector- and naive-phenotype $\mathrm{T}$ cells provide further support for the validity and accuracy of the FACS/stable isotope/mass spectrometric method $(12,24)$. The finding of shorter halflives for memory/effector-phenotype cells is consistent with extensive prior work in animal models $(3,4,7,19,20)$ and in humans $(6,21,22)$. Moreover, the sum of absolute production rates calculated for memory/effector plus naive phenotype $T$ cells was generally close to the absolute production rate of the total T-cell population (Table 2), even though all 3 were measured independently. Thus, both external and internal validation of the method is provided by these results.

The above observations suggest, in aggregate, that HIV-1-seropositive subjects may be subdivided into discrete groups with respect to the composition of the peripheral blood T-cell compartment. One group is typified by abundant thymic tissue, high circulating levels of slowly dividing naivephenotype T cells, and low turnover of the total circulating T-cell pool. Another is characterized by nonabundant thymic tissue, lower proportions of naive-phenotype $\mathrm{T}$ cells, and higher turnover of the total circulating T-cell pool. Given the presence or absence of abundant thymic tissue and naive $\mathrm{T}$ cells in the peripheral blood, the potential for diversification of the TCR repertoire may vary. It follows that the long-term sequelae of this distinction may be important: individuals in both groups may be able to produce new $T$ cells, but those dependent on extrathymic maturation alone may remain immunodeficient. By example, increased $\mathrm{CD} 4+\mathrm{T}$-cell responses to CMV have been found in some, but not all, late-stage subjects after the initiation of HAART (ref. 14; K.V. Komanduri et al., manuscript submitted for publication).

These results suggest that $\mathrm{CD} 4+$ and CD8+ T-cell production is inhibited by HIV-1 infection. After viral replication is suppressed by HAART, T-cell production once again resumes, be it driven by antigen-dependent or antigen- independent means. By inference, HIV-1 disease progression may be closely linked to lesions in T-cell production. To the extent that such lesions can be identified, it may be possible to design therapeutic modalities to delay progression of early HIV-1 disease and/or to facilitate recovery from late-stage HIV-1 disease.

\section{Acknowledgments}

We thank the individuals who participated in this study, as well as ACT UP Golden Gate, Project Inform, and other members of the San Francisco AIDS community for support, and the San Francisco General Hospital Department of Radiology for assistance with the CT scans. We also acknowledge the expert assistance of G. Veltri of the Gladstone Institute Core Flow Cytometry Laboratory. This work was supported by an Interactive Research Project Grant to J. M. McCune and to M. Hellerstein from the National Institutes of Health (NIH; AI43866) as well as grants from the NIH to J.M. McCune (AI43864 and AI40312) and to M. Hellerstein (AI41401 and AI44767) and from SpectruMedix. J.M. McCune is an Elizabeth Glaser Scientist supported by the Elizabeth Glaser Pediatric AIDS Foundation. An NIH Grant (5MO1-RR00083) from the Division of Research Resources supported the General Clinical Research Center.

1. Ho, D.D., et al. 1995. Rapid turnover of plasma virions and CD4 lymphocytes in HIV-1 infection. Nature. 373:123-126.

2. Wei, X., et al. 1995. Viral dynamics in human immunodeficiency virus type 1 infection. Nature. 373:117-122.

3. Mohri, H., Bonhoeffer, S., Monard, S., Perelson, A.S., and Ho, D.D. 1998. Rapid turnover of T lymphocytes in SIV-infected rhesus macaques. Science. 279:1223-1227.

4. Rosenzweig, M., et al. 1998. Increased rates of CD4+ and CD8+ T lymphocyte turnover in simian immunodeficiency virus-infected macaques. Proc. Natl. Acad. Sci. USA. 95:6388-6393.

5. Tenner-Racz, K., et al. 1998. The unenlarged lymph nodes of HIV-1-infected asymptomatic patients with high CD4 $\mathrm{T}$ cell counts are sites for virus replication and CD4 $\mathrm{T}$ cell proliferation. The impact of highly active antiretroviral therapy. J. Exp. Med. 187:949-959.

6. Sachsenberg, N., et al. 1998. Turnover of CD4+ and CD8+ T lymphocytes in HIV-1 infection as measured by Ki-67 antigen. J. Exp. Med. 187:1295-1303

7. Hellerstein, M.K., and McCune, J.M. 1997. T cell turnover in HIV-1 disease. Immunity. 7:583-589.

8. Clark, D.R., de Boer, R.J., Wolthers, K.C., and Miedema, F. 1999. T cell dynamics in HIV-1 infection. Adv. Immunol. 73:301-327.

9. Roederer, M., De Rosa, S.C., Watanabe, N., and Herzenberg, L.A. 1997. Dynamics of fine T-cell subsets during HIV disease and after thymic ablation by mediastinal irradiation. Semin. Immunol. 9:389-396.

10. Bucy, R.P., et al. 1999. Initial increase in blood CD4+ lymphocytes after HIV antiretroviral therapy reflects redistribution from lymphoid tissues. J. Clin. Invest. 103:1391-1398.

11. Pakker, N.G., et al. 1998. Biphasic kinetics of peripheral blood $\mathrm{T}$ cells after triple combination therapy in HIV-1 infection: a composite of redistribution and proliferation. Nat. Med. 2:208-214.

12. Hellerstein, M., et al. 1999. Directly measured kinetics of circulating $T$ lymphocytes in normal and HIV-1-infected humans. Nat. Med. 5:83-89.

13. Fleury, S., et al. 1998. Limited CD4+ T-cell renewal in early HIV-1 infection: effect of highly active antiretroviral therapy. Nat. Med. 4:794-801.

14. Komanduri, K.V., et al. 1998. Restoration of CMV-specific CD4+ T lymphocyte responses in HIV-1-infected individuals after ganciclovir and highly active antiretroviral therapy. Nat. Med. 4:953-956

15. Li, T.S., et al. 1998. Long-lasting recovery in CD4 T-cell function and viral-load reduction after highly active antiretroviral therapy in advanced HIV-1 disease. Lancet. 351:1682-1686.

16. Pontesilli, O., et al. 1999. Functional T cell reconstitution and human immunodeficiency virus-1specific cell-mediated immunity during highly active antiretroviral therapy. J. Infect. Dis. 180:76-86.

17. Pitcher, C.J., et al. 1999. HIV-1-specific CD4+ T cells are detectable in most individuals with active HIV-1 infection, but decline with prolonged viral suppression. Nat. Med. 5:518-525.

18. McCune, J.M., et al. 1998. High prevalence of thymic tissue in adults with HIV-1 infection. J. Clin. Invest. 101:2301-2308.

19. Tough, D.F., and Sprent, J. 1995. Life span of naive and memory T cells. Stem Cells. 13:242-249.

20. Ahmed, R., and Gray, D. 1996. Immunological memory and protective immunity: understanding their relation. Science. 272:54-60.

21. Michie, C.A., McLean, A., Alcock, C., and Beverley, P.C.L. 1992. Lifespan of human lymphocyte subsets defined by CD45 isoforms. Nature. 360:264-265.

22. McLean, A.R., and Michie, C.A. 1995. In vivo estimates of division and death rates of human T lymphocytes. Proc. Natl. Acad. Sci. USA. 92:3707-3711.

23. Roederer, M., et al. 1995. CD8 naive T cell counts decrease progressively in HIV-infected adults. $J$. Clin. Invest. 95:2061-2066.

24. Macallan, D., et al. 1998. Measurement of cell proliferation by labeling of deoxyribonucleic acid with stable isotope-labeled glucose: studies in vitro, in animals, and in humans. Proc. Natl. Acad. Sci. USA. 95:708-713.

25. Waterlow, J.C., Garlick, P.J., and Millward, D.J 1978. In Protein turnover in mammalian tissues and in the whole body. North-Holland Publishing. Amsterdam, The Netherlands. 216-219.

26. Hellerstein, M.K., and Neese, R. 1992. Mass isotopomer distribution analysis: a technique for measuring biosynthesis and turnover of polymers. Am. J. Physiol. 263:E988-E1001.

27. Douek, D.C., et al. 1998. Changes in thymic function with age and during the treatment of HIV infection. Nature. 396:690-695.

28. Poulin, J.-F., et al. 1999. Direct evidence for thymic function in adult humans. J. Exp. Med. 190:479-486.

29. Smith, K.Y., et al. 2000. Thymic size and lymphocyte restoration in HIV infected patients following 48 weeks of therapy with zidovudine, lamivudine, and ritonavir. J. Infect. Dis. 181:141-147. 